\title{
Roof Replacement of a Heritage Building Using Transparent Solutions: Room Acoustic Performance Comparison
}

\section{Macieira Mónica , Paulo Mendonça , João Miranda Guedes \& António P. O. Carvalho}

To cite this article: Macieira Mónica, Paulo Mendonça, João Miranda Guedes \& António P. O. Carvalho (2020): Roof Replacement of a Heritage Building Using Transparent Solutions: Room Acoustic Performance Comparison, International Journal of Architectural Heritage, DOI: 10.1080/15583058.2020.1777593

To link to this article: https://doi.org/10.1080/15583058.2020.1777593

曲 Published online: 22 Jun 2020.

Submit your article to this journal

View related articles

View Crossmark data $\rtimes$ 


\title{
Roof Replacement of a Heritage Building Using Transparent Solutions: Room Acoustic Performance Comparison
}

\author{
Macieira Mónica $\left(\mathbb{D}^{\mathrm{a}}{ }^{\mathrm{a}}\right.$, Paulo Mendonça $\mathbb{( D}^{\mathrm{a}}{ }^{\mathrm{a}}$, João Miranda Guedes $\mathbb{D}^{\mathrm{b}}$, and António P. O. Carvalho $\mathbb{D}^{c}$ \\ aSchool of Architecture/Lab2PT, University of Minho, Guimarães, Portugal; bFaculty of Engineering/Construct, University of Porto, Porto, \\ Portugal; 'Faculty of Engineering/Laboratory of Acoustics, University of Porto, Porto, Portugal
}

\begin{abstract}
Tensile membrane roofs are considered to have the potential to improve the buildings' performance due to their lightweight and flexible nature. However, their potential for improving acoustic behaviour has hardly been accurately gauged or demonstrated due to their complexity in both geometric and physical aspects. To address this issue, Carmo's church in Lisbon-a heritage building that lost the roof during the 1755 earthquake and is nowadays a museum-was selected as case study to analyse the impact of covering high complex volumes in room acoustics by using a conventional and an alternative transparent solution: (i) a single glazing and (ii) a simple and transparent ETFE membrane tensioned in a self-supporting metal structure. This last solution is combined with a retractable cross-vaulted ceiling in a translucent and acoustic absorbent membrane supported by pneumatic ribs. The acoustic performance for music and speech emission of these two options is compared to each other and to the existing scenario-without roof-through numerical modelling and by considering a set of selected parameters: Reverberation Time, Clarity, Early Decay Time, Speech Transmission Index and Definition $\left(D_{50}\right)$. These analyses allowed verifying the potential of membrane solutions to improve the acoustics of high complex volumes.
\end{abstract}

\section{ARTICLE HISTORY}

Received 23 September 2019

Accepted 31 May 2020

\section{KEYWORDS}

Acoustic performance simulation; architectural membrane materials; functional refurbishment; historical constructions; tensile membrane roof

\section{Introduction}

The initial premise of the research behind this work is that the relative efficiency of refurbishment solutions using architectural membranes needs to be evaluated, in order to allow its comparison with conventional solutions, helping decision makers on the selection process. The evaluation of this efficiency depends on functional features, but also on economical, technological and environmental ones. This paper presents a preliminary evaluation of the acoustic behaviour of a complex high volume Historical Construction $(H C)$ and the impact of the use of architectural thin/lightweight solutions and materials, at the top, may have on the building's acoustic performance. It will also evaluate the possibility of increasing sound absorption of these solutions using materials that provide absorption in the higher frequencies, but still enable natural light entrance.

The need to preserve Historical Constructions (HC) is not only a cultural requirement but also an economic and developmental demand in the 3rd millennium. This implies that any intervention on an $H C$, for functional or structural requirements, should respect the original construction characteristics, i.e. should adopt solutions that are, as far as practicable, reversible and proportional and have the least possible impact. Tensile membrane solutions meet these criteria and, therefore, the main entities involved with world heritage preservation have progressively supported the implementation of solutions with membranes to intervene on architectural heritage (Zanelli 2015); they guarantee high standards of protection, using flexible and reversible solutions (Macieira, Mendonça, and Guedes 2017).

However, the acoustic performance improvement due to the use of membranes has hardly been accurately gauged or demonstrated, due to their geometric and physical complexity. This study addresses this issue to a specific rehabilitation context-the restitution of the roof of Carmo's church ruins (now converted into the Carmo's Archaeological Museum-MAC), located in Lisbon, Portugal.

The purpose of this intervention would be to improve the functional characteristics of the building, with a complex high volume room, namely to promote proper usage conditions as cultural visiting place, and reduce the vulnerability of the building and of the unique and irreplaceable objects that are part of the museum it hosts, to natural events (e.g. weather conditions). Furthermore, being in Lisbon, a city with moderate to high seismic risk, it is fundamental to evaluate the impact of any 
intervention on the building seismic behaviour. Lightweight solutions using membranes can mitigate the effects caused by the occurrence of earthquakes, due to its high flexible and benign failure mode. In opposition, these same characteristics, low weight and small thickness, make membrane materials per se (considering coated/uncoated textiles or foils) to have low thermal and acoustic insulation values. Thus, in a space enclosed by these materials, the achievement of good acoustic conditions must be carried out through design (Monjo Carrió 1985). However, when applied to a building with heavy constructive elements, membrane solutions can improve (by adjusting its acoustic absorbent features) the existing conditions and be an efficient alternative to conventional solutions.

\section{Objectives}

This study addresses the acoustic improvement of complex high volume spaces through membrane solutions, using for this purpose a specific rehabilitation contextthe restitution of the roof of Carmo's church ruins (now converted into the Carmo's Archaeological MuseumMAC), located in Lisbon, Portugal.

Currently, the church's main nave has no roof and is as multiuse space where different kinds of events take place, especially in Summer. According to the information provided by $M A C$, in the last four years most of the events that occurred at the nave's space were oriented to music emission (choirs, symphony and semi-classic concerts) (Figure 1a). On the contrary, those that took place in the MAC's indoor auditorium, which has a very limited seating capacity (currently 50 seats, with possible expansion up to 90 seats), were related to word emission (conferences, colloquiums, lectures, theatre, etc.) (Figure 1b). However, most of the total events carried out at MAC in the last four years took place at the indoor auditorium (Figure 1c).
This paper measures the acoustic performance of the nave's space for both music and word emission. In particular, it evaluates the quality of events associated to speech that already take place at the nave's space (e.g. theatre) and analyses the possibility to transfer other speech events from the indoor auditorium to this space, taking advantage of its higher capacity to accommodate people (approx. 300 to 500 seated and 500 to 600 standing). However, there will always be speech events that can only be carried out at the auditorium, such as conferences, due to lightning requirements for image's projection during daylight hours.

The present exercise will consider the nave's space as it is, and with two different solutions that replace the roof: one using glass and the other membranes, to determine the influence that the roof and ceiling in membrane have on the acoustic performance of spaces with similar characteristics of the building taken as case study. The study will focus on the nave's performance for music and speech emission events.

\subsection{Earlier presence of membrane solutions for "acoustic rehabilitation" of high volume spaces}

By the growth of interdisciplinary studies, the acknowledgement of acoustical heritage as part of the architectural heritage concept drove to several studies (Carvalho 1994; Karabiber and Denli 1997; Tronchim and Coralli 2010). In particular, the assessment of the acoustic properties of historical buildings provides important complementary information related to cultural heritage.

Most monumental churches are under historical and artistic constraints, which, for aesthetic, architectural and conservation reasons, do not allow installing traditional sound-absorbing panels onto the walls. Recently, many researchers have looked at the roof of high volume churches, analysing solutions that represent compromises between acoustics and aesthetic values.

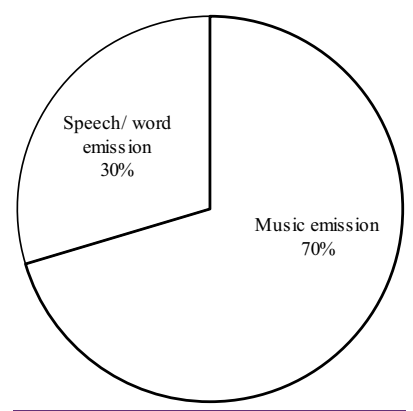

(a)

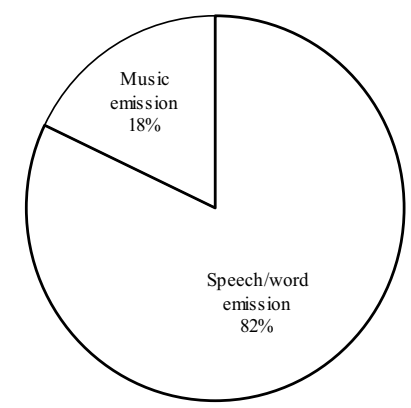

(b)

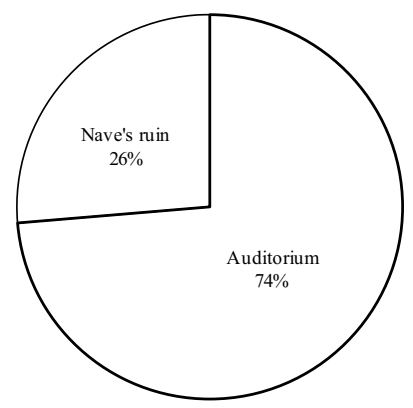

(c)

Figure 1. Distribution (percentage) of acoustic event's type and location at Carmo's church/MAC from 2015 to 2018 (information gently provided by MAC): (a) nave's ruins; (b) indoor auditorium; (c) events per location. 
Monumental churches present problems for speech understanding due to their high volume and presence of reflective material. The acoustic measurements of an empty large church provide an average reverberation time of about $10 \mathrm{~s}$, which does not provide very good conditions to either understand speech or listen to musical performances (Iannace 2016). To reduce reverberation time, it would be necessary to adopt innovative solutions that respect these constraints. For example, transparent micro-perforated sheets can be installed to correct the acoustic of the room, and still respect the aesthetic constraints-the historical-architectural and artistic characteristics (Álvarez-Morales et al. 2014; Lombardi et al. 2017; Lombardi and Trematerra 2018). As an example, Iannace (2016) recommended the introduction of acoustic resonators made of micro-perforated transparent sheets for medium and high frequencies.

Navarro, Sendra, and Muñoz (2009), in the analysis of the evolution of acoustic conditions in churches, describe several uses of carpets and pendants/curtains (also considered membrane materials, but without structural function) in churches and analyse its effect on the acoustics of these places, especially in the baroque period: "(...)church ornaments actions, especially used for religious and civil celebrations" could also be considered acoustic improvement actions, as "(...) the abundance of carpet and pendants, velvet and damask/ jacquards, and the profuse general decoration, combined with the large number of people (who in turn were dressed in large and heavy fabrics) could only increase the sound absorption of these churches, reducing echoes and high reverberations, which are serious acoustic defects".

Another example of the use of membrane materials in acoustic buildings improvement is the Crystal Palace (19th century) in Sydenham, London, designed by Joseph Paxton, with $540 \mathrm{~m}$ wide; it was the first and bigger glass and iron palace intended for music. As a comment on the acoustics of this hall, based on Forsyth and Charlie Greville reports (Simões 2000), it is considered that glass walls provide sound absorption of low frequencies. The huge audience (around 88,000 people) coupled with the presence of a large number of curtains and awnings inside provided the absorption of medium and high-frequency sounds. High absorption throughout the range of audible frequencies made the place sound like an open space.

Regarding 20th century examples, Berger (1996) refers to the achieved effect at Bullock's Mall (California): "On a wooden frame of crossed arches the double fabric membrane $\left(1400 \mathrm{~m}^{2}\right)$ admits $7.7 \%$ of light that hits it. It also absorbs sound with a porous lower skin and improves the structure's acoustics". Other roof shapes-Shoreline Amphitheatre $\left(8000 \mathrm{~m}^{2}\right)$ and
Cynthia Woods Mitchell Performing Arts Centre $\left(2600 \mathrm{~m}^{2}\right)$-are also considered as acoustically good "by eliminating focused echoes" (Berger 1996).

These examples show that membranes placed either for decoration or acoustics purpose can be useful elements to improve the acoustics of a space. In any case, despite the mentioned historical background, there are few references that summarize and discuss the acoustic behaviour of membrane structures in the past (Chemlik et al. 2015; Llorens and Soldevila 1991; Monjo Carrió 1985; Simões 2000).

\subsection{Review of acoustic comfort of membrane structures}

Membrane structures are mostly used to form roofs. The most common are temporary or permanent structures for sport halls, stadiums, places for music festivals or large receptions. These structures can offer significant weight saving; their great potential is in their high tensile strength, flexibility (e.g. to create organic shapes), long lifespan, translucency, low construction and maintenance costs. Although membrane structures can cover huge spaces with free spans and save electricity for illumination because of their light transmission properties, they have also some shortcomings. Their configured spaces have often acoustic problems such as flutter echo, standing waves, sound focusing and strong late reflections (later than $100 \mathrm{~m}$ ), which significantly decrease speech intelligibility (Nocera et al. 2014). Often reported shortcomings are reverberation, low sound absorption, rain-noise problems, weak sound and thermal insulation performance (Chemlik et al. 2015; Nocera et al. 2014; Simões 2000).

To ensure acoustic comfort with such structures is not easy, since the technologies commonly used for traditional structures do not work for lightweight ones (Dlhy and Minarovicova 2014). Probably, the most interesting applications on this domain are on acoustic components, as multilayer membrane-type structures and micro-perforated and double-leaf absorbers, for example. Considering rain noise, it is possible to insulate by adding absorptive layers and damping materials to the lightweight membrane roof structure. Placing a good shock-absorbent material has a strong influence on the rain-noise reduction and improves performance at high frequencies (Chiu, Noble, and Valmont 2015; Toyoda and Takahashi 2013).

Simões (2000) findings give important guidelines to design membrane solutions in order to achieve acoustic comfort spaces:

- architectural membranes are very transparent for low frequencies due to its low mass and, as they are 
very reflective for medium and high frequencies, they may cause excessive reverberation times from $1000 \mathrm{~Hz}$ onwards; therefore, in the design of such spaces, the interior volume must be controlled, because volume is in direct relation to reverberation time (according to Sabine's formula (Joyce 1974));

- in large spaces, given the importance of the membrane covering surfaces and their dimension, it is possible to achieve significant sound absorption by employing a double membrane, being the interior one porous and permeable;

- the lightness of the membranes produces low acoustic insulation, which contributes to reduce the speech intelligibility indexes; the main way to combat this negative aspect of environmental control would be prevention. For instance, one can rule disturbing noise sources, such as vehicle traffic, by making proper urban planning decisions; the use of acoustic barriers, made with suitable vegetation or materials (there are many patents on the market) can also help to significantly mitigate the effects of noise. Sound transmission through thin membranes could possibly be reduced in some frequencies by making them inhomogeneous. Some studies point out that it is possible to improve sound insulation efficiency by attaching small weights to a membrane, resulting in so-called membranes with additional weights (MAW) (Novak 2004).

\subsection{Examples of membrane solutions for heritage/ old buildings refurbishment}

There are a lot of different kinds of membranes: textiles (coated or uncoated, woven, non-woven, knitted, etc.) and foils (perforated or not). Their acoustic properties in relation to architectural design can be investigated from different points of view. The most common studies refer to their properties in relation to (1) room acoustics, e.g. sound absorption, and (2) building acoustics, e.g. sound insulation, and both contribute to the overall acoustic comfort.

\subsubsection{Building acoustics}

Covering a ruined building, a courtyard, or an archaeological site with membrane is a frequent solution to protect a construction/site and promote functional rehabilitation, making these spaces more dynamic (Macieira, Mendonça, and Guedes 2017). To illustrate this, some examples of membrane roofing design for building's functional rehabilitation are presented, giving special attention to the acoustic performance. The following projects are also examples of the effectiveness of membrane structures to preserve existing constructions.

Inevitably, the use of new technologies and materials to preserve, extend, or replace an existing building element confronts itself with intrusiveness matters. The low intrusiveness of membrane solutions, coupled with acoustic and day lighting advantages, were behind the design of several large skylights for covering courtyards using pneumatic membrane (double or triple layer) technologies: Dresden Castle/Kleiner Schlosshof (by Peter Kulka, Germany); Museo Chileno de Arte Precolombino (by Smiljan Radic, Chile); Kapuzinercarrée (by Ingenhoven \& Partne, Germany); Igartza Palace (by Zulueta, Spain).

Translucent and single-layer membrane design solutions also worth being mentioned, namely: (1) membrane roofs of Vienna City Hall's courtyard (by Tillner \& Willinger) and of Salzburg Palace (by Kugel), both designed to be totally reversible and retractable, in order to provide protection against climatic variations, allowing organizing different cultural events-its wave surfaces contribute for an optimized sound's distribution in musical events; (2) membrane roof of the Academy of Arts courtyard in Mons (by AgwA + Ney \& Partners) that consists of five modular and independent membrane vaults-the geometry created by the membrane arches promotes good acoustic performance of the covered outer space and its translucency allows for maximum luminosity, without compromising the daylight gains inside the existing building.

\subsubsection{Room acoustics}

Several studies point out the benefits of applying porous/ permeable membranes for acoustic performance improvement of interior spaces. There are several examples of membrane solutions applied to ceilings, especially in large spaces of existent heritage buildings. Four projects carried out in the last 20 years are presented.

With the aim to use the Schlüterhof Museum's courtyard (Berlin, Germany) all year, a glass roof was designed. However, after its execution, it was found that the reverberation time in the courtyard was too high and echo problems arose due to the reduced sound absorption of existing materials. The acoustic measurements showed that it would not be possible to host events with or without musical performance, even with electroacoustic means. To solve this problem, it was implemented a suspended ceiling (designed by I. M. Pei) composed of a cable and metal rods net, connected to the glass cover's perimeter, where two layers of a PVC membrane (micro-perforated and translucent) were placed, kept $15 \mathrm{~cm}$ apart from each other through springs. The membrane's absorption and refraction effect reduced the reverberation time (Nocke, Hilde 
and Scherrer 2016), allowing performing musical events. Furthermore, the membrane's translucency did not change the aesthetics of this space.

Another example is the St. Petri-Pauli church's (Eisleben, Germany) that has, predominantly, reflecting surfaces. In order to greatly reduce the reverberation time on the nave's space, a micro-perforated membrane covering (designed by Rehder) was applied to the existing massive ceiling; the optimum amount of sound absorption can be achieved by selecting the right distance between the membrane and the ceiling above (Maa 1975; Nocke, Hilge, and Scherrer 2011).

The Dominican Holy Cross Elevation church, kostel Povýšenísv. Křžze (Jihlava, Czech Republic), built in 13th century under the French Gothic's style influence, was acoustically improved in 2011, by the reconstitution of its presbytery's vaulted ceiling, using a stretched and micro-perforated membrane (designed by Martin Laštovička). Another similar approach was followed at the Dargun monastery (Dargun, Germany), built in the 13th century and rehabilitated in 2014. A suspended ceiling made off a permeable polyester membrane (designed by Beyer) was introduced as a substitute for the original gothic stone vaults. The reverberation time on the nave's space was uniformly reduced for all sound frequencies and the light reflection/diffusion was improved.

The millenary Benedictine Abbey of Pannonhalma (Abbatia Territorialis Sancti Martini in Monte Pannoniae), UNESCO World Heritage Site (Pannonhalma, Hungary), is one of the oldest monuments in Hungary and was transformed into a college. Since 2005, it hosts the Pannonhalma Arcus Temporum festival and, for it to happen, there was the need to transform and adapt the gymnasium of the college to a different use, with a reduced budget. For this purpose, an installation suspended from the ceiling (designed by Dániel Baló et al.) was built with several layers of a translucent polypropylene membrane, offset and arranged parallel to each other. Each layer presents a section specifically designed to control the sound absorption and propagation, resulting in a three-dimensional wave, through which the acoustic enhancement of the gym was achieved, dampening and dispersing the loudest sounds through space (Yatzer 2016). In addition, the translucency of the membrane created a suitable interior environment to classical music performances, fading the characteristic look of the gym.

\section{Case study: ruins of a 14th-century church}

The Carmo's church, as it is usually known (its official name is Church of Our Lady of Mount Carmel), listed as national monument, was erected in 1389 , together with its convent ensemble, in Lisbon, Portugal. Until Lisbon's 1755 earthquake, it was the largest gothic monument of Lisbon. During the earthquake, and the subsequent fire, Carmo's church suffered great damage that caused the collapse of a large part of the structure, creating a ruin. It is about 70 meters long and its main body contains three naves (Figure $2 b$ ): the central one was originally covered by a pitch-roof and the side naves by a one slope roof (Arnault and Fernandes 2005). Only the head, the main façade, few fractions of the north and south walls and some of the cross pointed arches that supported the collapsed nave's ceiling, are currently standing (Figure 2b-d) (Pereira 2017). The decision to maintain the nave open to the sky resulted from the lack of financial resources to rebuild it, but also from a certain position assumed in the conservation and restoration theory

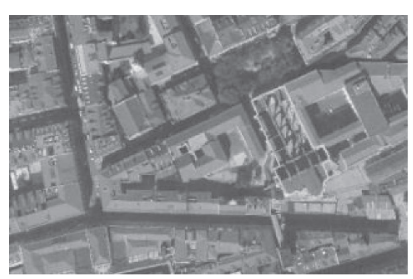

(a)

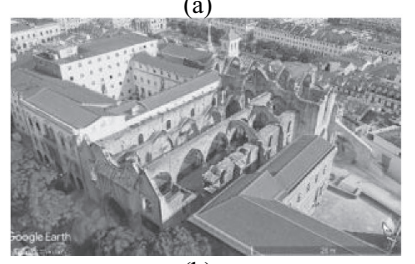

(b)

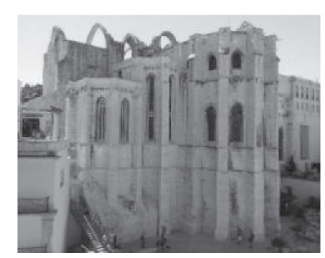

(c)

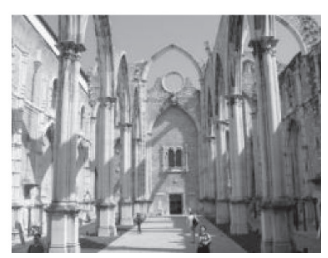

(d)

Figure 2. Carmo's church views: (a) Orthophoto map with its location; (b) aerial view retrieved from Google Earth (credits to: Landsat/ Copernicus); (c) exterior view of the main chapel from Santa Justa lift; (d) interior view of the nave. 


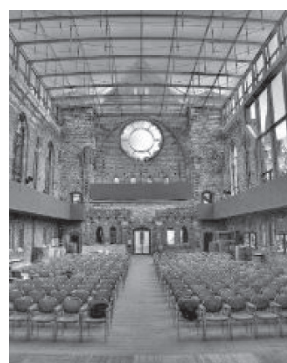

(a)

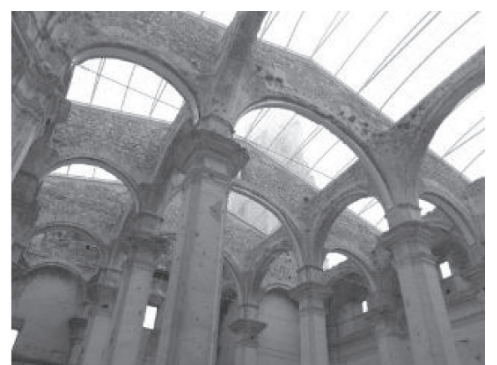

(b)
Figure 3. Example of skylights to replace roofs of old churches that collapsed, being converted into multipurpose halls: (a) glass roof of Theaterruine St. Pauli, former church St. Pauli's church in Dresden, Germany (credit photo attributed to Pauliruine under the license CC BY 3.0, photo changed to greyscale, available on Wikimedia Commons); (b) single ETFE membrane roof (designed by Ferran Vizoso architect) of S. Pedro's heritage church in Corbera d'Ebre, Spain (credit photo attributed to Enric under the license CC BY-SA 4.0, photo changed to greyscale, available on Wikimedia Commons).

since, at least, the first quarter of the 19th century (Monumentos 2017). Irrespective of the reason, the ruin of the church remained as a memorial of the 1755 earthquake that strongly affected Lisbon and its inhabitants.

Currently, the uncovered church's nave exhibits the archaeological findings of the Museum of Archaeology of Carmo (MAC) that is installed in the church. However, the missing roof is not only exposing to deterioration of the ruins and the archaeological pieces arranged in the church's nave, as it limits the number of cultural and social activities that may take place. For these reasons, covering this space would allow to expose/ store more archaeological pieces and to promote a greater number of events throughout the year.

The idea of the transparent cover follows the proposal made in 1864 by the MAC founder, the architect Possidónio da Silva, which reflects the need to maintain, as much as possible, the ruins' character, preserving the existing architectural language and the feeling of being outdoors, keeping the church's nave opened to the sky and illuminated by natural light. In addition, to replace the original ceiling and achieve luminous and acoustic comfort suitable to the nave's space new requirements, an adjustable ceiling solution is also proposed (in addition to the roof s replacement): a retractable cross vault ceiling made of translucent textile membrane.

Nowadays, other architects share Possidónio's vision. There are examples of refurbishment interventions that replace missing roofs in old buildings by large skylights made of glass or membrane, as those presented in Figure 3.

\section{Materials and methods}

\subsection{Refurbishment solutions under evaluation}

It was considered two solutions to replace the roof and ceiling of Carmo's church: a conventional one using a Glass Roof (GR) and an alternative using a Membrane Roof with a Retractile Membrane Ceiling $(M R+R M C)$ (Figure 4). Since this study involves a national monument, the design of the solutions had to take into account such issues as the intrusiveness in the building and architectural preservation, coupled with features such as acoustic comfort, safety and protection of the users. The acoustic performance of the two solutions (GR and $M R+R M C$ ) was evaluated for multipurpose uses, but more in particular for music emission events, being compared to the existent scenario Without Roof (WR) (Figure 4).

\subsubsection{Conventional solution}

The conventional roof's replacement solution GR consists of a fixed structure in laminated single glazing (12 mm thick) with a self-supporting metal frame.

\subsubsection{Alternative solution}

The alternative solution $M R+R M C$ consists of a lightweight roof cover made of an ETFE (ethylene tetrafluoroethylene) membrane, tensioned in a selfsupporting metal structure (Figure $5 b$ ). In this study, it is assumed fixed, as the $G R$, but it can be retractable. This solution allows covering the space with low additional load applied to the existing structural elements.

In addition, an adjustable ceiling solution is proposed to complement the transparent roof, in order to achieve luminous and acoustic comfort suitable to transform the nave into a multifunctional space; it permits to adapt the space to variable natural lighting and acoustic requirements. To be closer to the visual gothic language of the monument's original style, the ceiling will create rib vaults made of a single membrane of high tenacity polyester (that has acoustic absorbent properties and transmits $41 \%$ of light) and pneumatic membrane ribs made of a neoprene and $P V C$ coated polyester membrane (Figure 5a).

To host different cultural events throughout the year (with daily and seasonal climatic variants), there is the need to adopt a dynamic solution to regulate adverse acoustic and lighting conditions, to maximize the use of the nave's space. In particular, it should allow: (1) including shader/light diffusor (as it is expected that glare discomfort occurs, so the retractable ceiling also acts as a shader/light diffusor for this giant "skylight"); (2) reducing reverberation time for certain events (associated with speech or some music types); (3) open-air 
WR - Space Without Roof (current status).

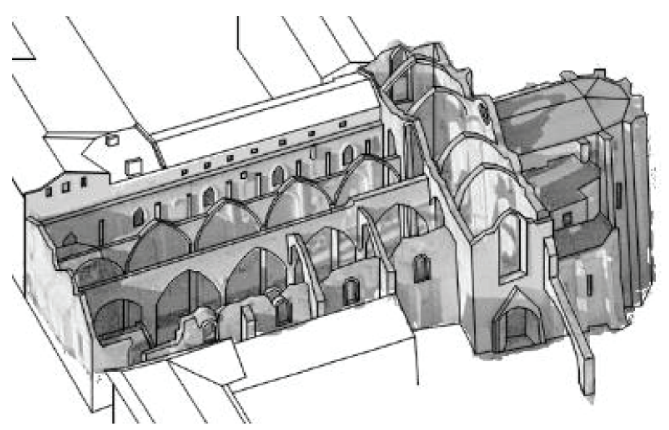

GR - Laminated Glass Roof (12 mm thick) with $86 \%$ transmission of visible light.
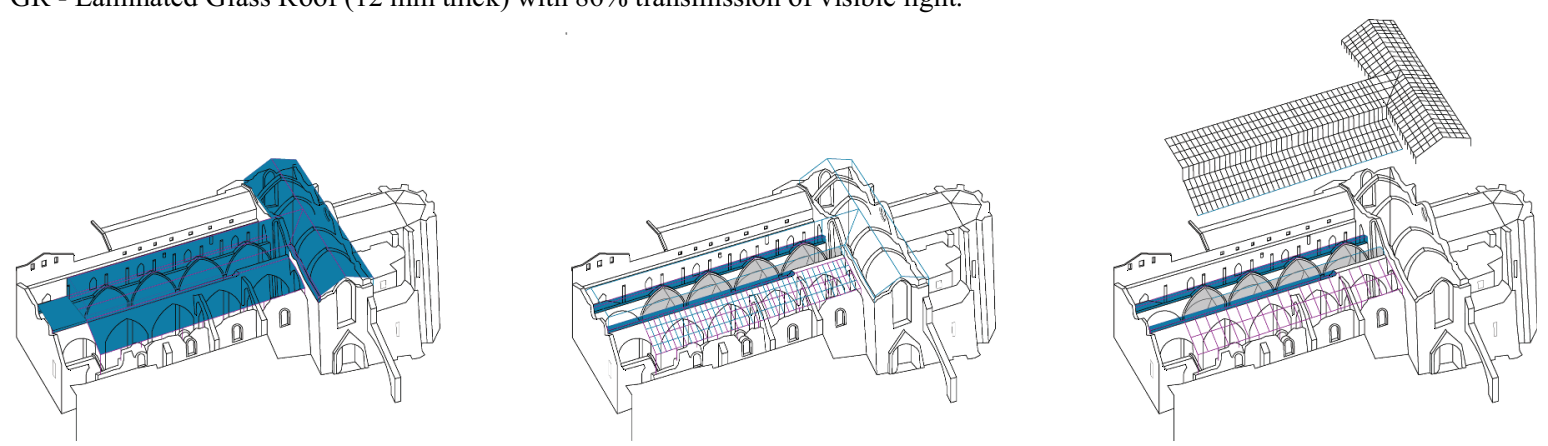

$\mathrm{MR}+\mathrm{RMC}$

Single ETFE Membrane Roof $(0.3 \mathrm{~mm})$ with $89 \%$ transmission of visible light;

Retractable Membrane Ceiling with $40 \%$ transmission of visible light (made off an acoustic absorbent membrane material).
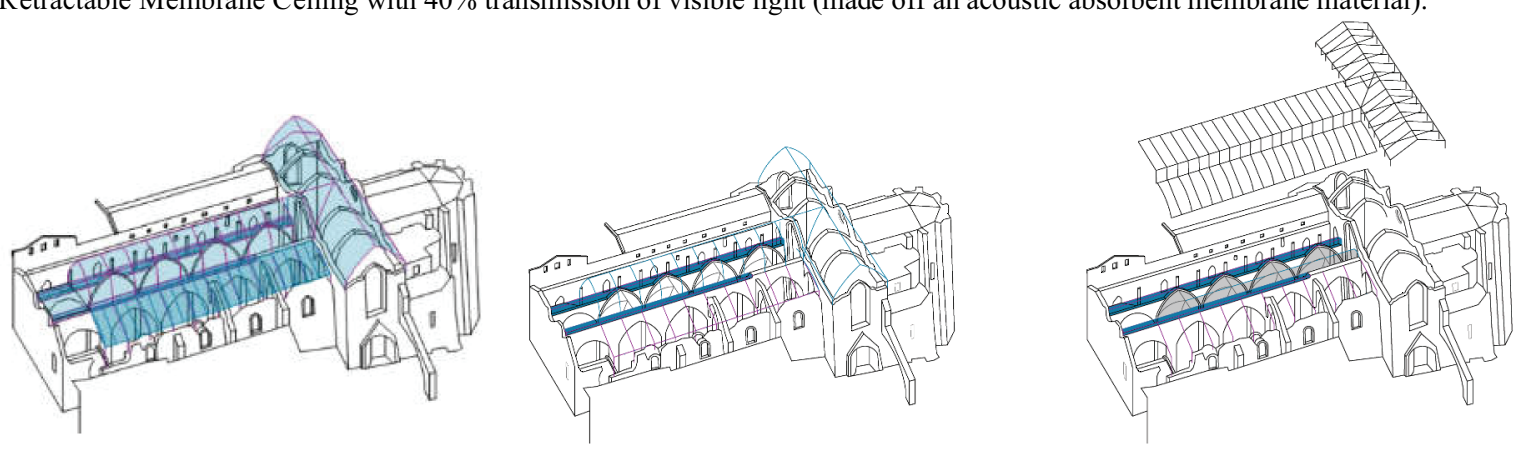

Figure 4. Overview of Carmo's church ruins/MAC with all solutions' configurations under evaluation.

ruin feeling; and (4) increasing the reverberation time for certain musical events. For (2) the ceiling should be extended (Figure 6b) and for (3) and (4) the ceiling should be retracted (Figure $6 \mathrm{c}$ ).

By gathering the retractable ceiling, it will close/cover the entrance area of MAC where the stairs (also used as audience seats) are located. They are currently used by the visitors to sit, relax and appreciate the ruins' open sky view and will be permanently shaded. Note that the proposed roofing structure is reversible, i.e. it can be assembled and disassembled, guarantying that the building listed as National Monument will not be permanently changed.

In synthesis, the proposed alternative refurbishment solution results from the combination of an ETFE membrane roof with a retractable cross-vaulted ceiling in a polyester membrane with acoustic absorbent properties.

\subsection{Selected tool for numerical simulation}

The computer tool used to calculate the acoustic performance of the solutions' configurations was Olive Tree Lab (OTL), Suite Room version 4.3 (PEMARD 2018). The choice of OTL suit-room was made because it allows: (1) 3D acoustic modelling in an integrated work environment; (2) measuring flat waves' propagation and sound absorption coefficients; (3) creating multilayer structures based on the transfer matrix method; and (4) measuring Reverberation Time $(R T)$, Early Decay Time $(E D T)$, Definition $\left(D_{50}\right)$ and Clarity $\left(C_{80}\right)$, using $3 \mathrm{D}$ models-this is particularly relevant for this case study, as the configuration of the proposed solutions presents peculiar geometric characteristics. 


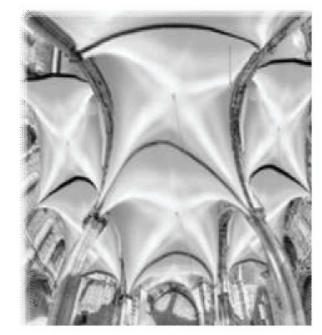

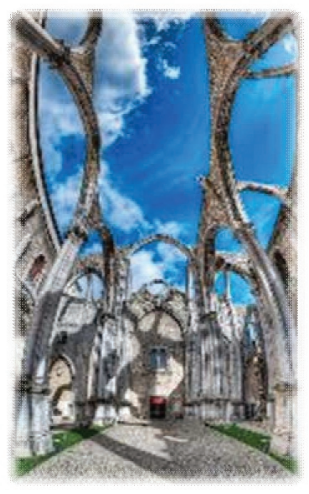

(a)

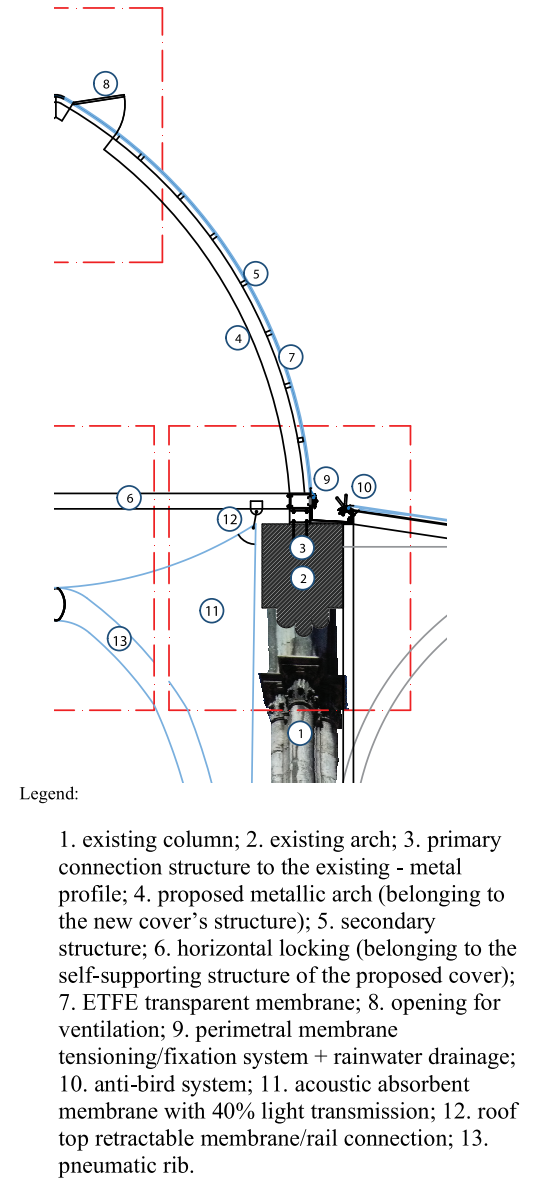

(b)

Figure 5. (a) Virtual interior view of Carmo's church/MAC with and without the proposed retractable cross vault membrane ceiling. (b) detail of roof and ceiling membrane solution connected to the existent building elements.

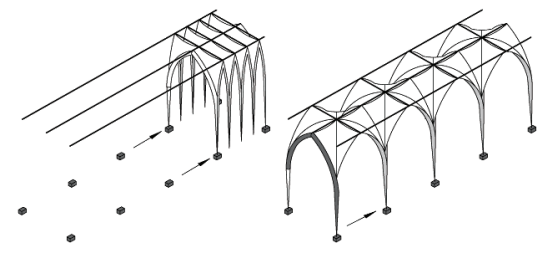

(a)

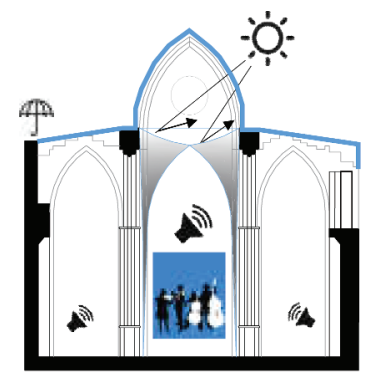

(b)

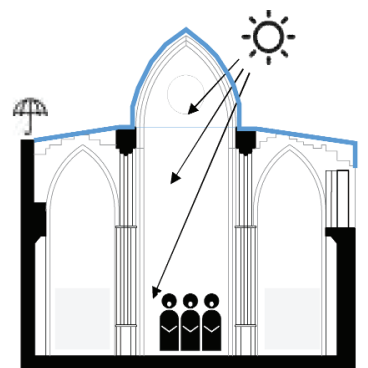

(c)

Figure 6. Scheme of the adopted concept: (a) retractable operation system; scenarios with the permanent and fixed transparent cover and the translucent vaulted ceiling (b) extended (e.g. for shading or acoustical activities that require lower reverberation time $(R T)$ ) and (c) retracted (e.g. for acoustical activities that require higher $R T$ ).

\subsection{Method}

The acoustical characteristic of a space is determined by the degree of speech intelligibility and/or the quality of the auditory perception caused by the music. As the nave's space has been used for speech (30\%) and musical events (70\%), the evaluation of Carmo's church/MAC's acoustic performance for the proposed refurbishment solutions is made for both speech intelligibility and musical perception, using the following parameters: Reverberation Time $(R T)$, Early Decay Time (EDT), 
Clarity $\left(C_{80}\right)$ (these first three related to musical intelligibility), Speech Transmission Index (STI) and Definition $\left(D_{50}\right)$ (these last two related to the perception of word).

The OTL suit-room calculates sound propagation based on Pemard's methodology, reported by Charalampous and Economou (2016), that focuses on preserving the nature of Wave-Based Geometrical Acoustics (WBGA) (Lam 2005) and uses simplifications only in cases where there is no alternative. The calculation options apply to the following standards: ISO 33821 (2009), ISO 3382-2 (2008), ISO 3382-3 (2012) and IEC 60268-16 (2011).

\subsection{Modelling}

The simulations implied a set of actions: (a) transfer the 3D model, created in the SketchUp software tool, for the OTL suit-room (Figure 7); (b) to assign materials to the surfaces according to their physical properties and sound absorption coefficients, or by calculating their surface impedance; (c) to position the receivers at $1.2 \mathrm{~m}$ height and the noise sources at $3.0 \mathrm{~m}$ height; (d) to assign actual sources and receivers and (e) run calculations, for single or multiple receivers, for indoor acoustics.

Regarding the influence of the form, Bouillart ( apud Simões 2000), in the study of pools covered by tensile membranes, points out that the walls of the indoor pools should be as diffusive as possible, with non-parallel sides, with many curtains and ornaments, providing reflective convex surfaces. The most common forms in tensioned membrane covers are hypar, i.e. anticlastic. However, the anticlastic surfaces are neither concave or convex. According to Simões (2000) special attention should be paid to this problem when modelling and doing simulations. Tangent planes to the membrane surface must be determined, at the points where the sound ray touches the membrane, in order to establish incidence and reflection angles.

\subsection{Input data}

To implement the acoustic performance simulation, it is assumed, as input data, an outside noise level of $75 \mathrm{~dB}(\mathrm{~A})$ and inside noise level of $53 \mathrm{~dB}(\mathrm{~A})$, based on experimental results collected in situ (by the authors) on Carmo's church nave's ruin. Moreover, it is considered that the nave's space is unoccupied, not air conditioned and is for musical events (not electro-acoustically supported). The position of the sound sources and sound receivers, considered to adequately define the actual acoustic behaviour of the space under analysis, is presented in Figure 8, which also presents a summary of the dimensional and surface materials characteristics of the church's interior space. Table 1 presents the properties of the considered materials.

To carry out the comparative analysis between the existing building without roof $(W R)$-an exterior space -and with the two roof solutions (GR and $M R$ ) -an interior space-it was considered that WR presents

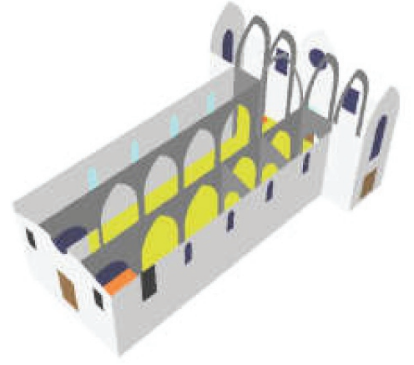

WR
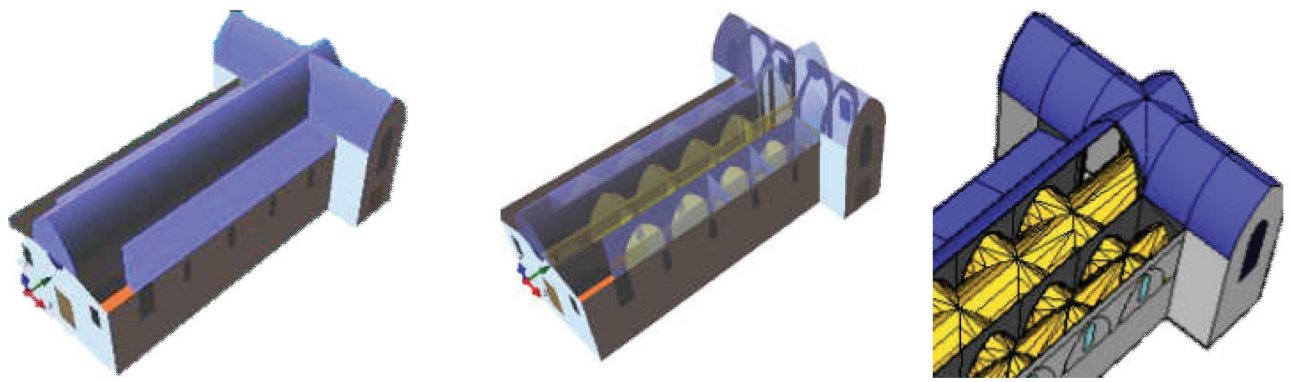

Figure 7. Virtual building models of the configurations/solutions under evaluation. 


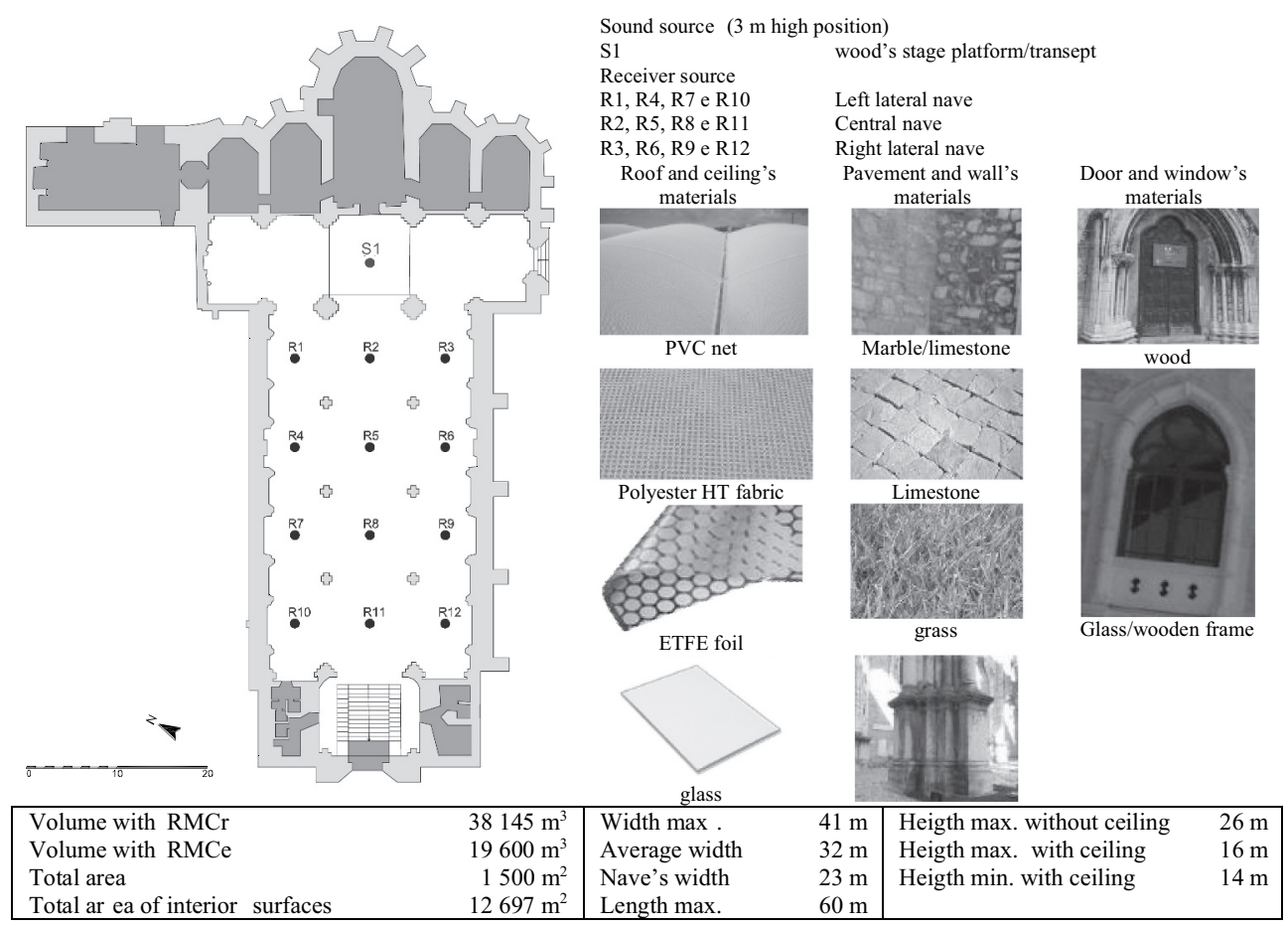

Figure 8. Dimensional characteristics of the case study's space and the location of the measuring points (sound sources and receivers) considered in the numerical simulations.

Table 1. Physical properties and sound absorption coefficients of the materials considered in the numerical simulations (calculated and retrieved from databases).

\begin{tabular}{|c|c|c|c|c|c|c|c|c|c|}
\hline \multirow[b]{2}{*}{ Solution for roof and ceiling } & \multirow[b]{2}{*}{ Materials } & \multirow{2}{*}{$\begin{array}{c}\begin{array}{c}\text { Superficial } \\
\text { area }\end{array} \\
\left(\mathrm{m}^{2}\right)\end{array}$} & \multirow{2}{*}{$\begin{array}{l}\text { Weight } \\
\left(\mathrm{kg} / \mathrm{m}^{2}\right)\end{array}$} & \multicolumn{6}{|c|}{$\begin{array}{l}\text { Frequency bands }(\mathrm{Hz}) \\
\text { Sound Absorption Coefficient }\end{array}$} \\
\hline & & & & 125 & 250 & 500 & 1000 & 2000 & 4000 \\
\hline WR (space Without Roof) & "Virtual roof" (air) & 2500 & & 1.00 & 1.00 & 1.00 & 1.00 & 1.00 & 1.00 \\
\hline GR (Glass Roof) & laminated glass (12 mm) & 2500 & 30.00 & 0.18 & 0.06 & 0.04 & 0.03 & 0.02 & 0.02 \\
\hline \multirow[t]{2}{*}{ MR (Membrane Roof) } & ETFE membrane $(0.3 \mathrm{~mm})$ & 2500 & 0.53 & 0.78 & 0.47 & 0.19 & 0.06 & 0.02 & 0.01 \\
\hline & $\begin{array}{l}\text { PVC rain noise suppression net - perforation with } \varnothing 90 \mathrm{~mm} \\
(1 \mathrm{~mm}) ; 53 \% \text { openness; } 0.44 \mathrm{~kg} / \mathrm{m}^{2}\end{array}$ & 2500 & 0.44 & & & & & & \\
\hline $\begin{array}{l}\text { RMC (Retractable Membrane } \\
\text { Ceiling-) }\end{array}$ & $\begin{array}{l}\text { Polyester membrane fabric with open mesh ( } 40 \% \text { transmission } \\
\text { of visible light) }\end{array}$ & 2030 & 0.60 & 0.20 & 0.60 & 0.80 & 0.90 & 0.95 & 1.00 \\
\hline \multicolumn{10}{|c|}{ Walls/pavements and others: } \\
\hline \multicolumn{2}{|c|}{ Occupied chairs (reduced upholstery) } & 900 & & 0.51 & 0.64 & 0.75 & 0.80 & 0.82 & 0.83 \\
\hline \multicolumn{2}{|c|}{ Empty chairs (reduced upholstery) } & 900 & & 0.36 & 0.47 & 0.57 & 0.62 & 0.62 & 0.60 \\
\hline \multicolumn{2}{|c|}{ Wooden doors } & 120 & & 0.30 & 0.25 & 0.20 & 0.17 & 0.15 & 0.10 \\
\hline \multicolumn{2}{|l|}{ Marble/Limestone } & 7100 & & 0.02 & 0.02 & 0.03 & 0.04 & 0.05 & 0.05 \\
\hline \multicolumn{2}{|l|}{ Grass } & 90 & & 0.10 & 0.16 & 0.26 & 0.39 & 0.56 & 0.73 \\
\hline \multicolumn{2}{|l|}{ Existing Glass Windows (4 mm) } & 35 & & 0.18 & 0.06 & 0.04 & 0.03 & 0.02 & 0.02 \\
\hline \multicolumn{2}{|c|}{ Window hole closure with ETFE membrane $(0.3 \mathrm{~mm})$} & 120 & & 0.79 & 0.48 & 0.20 & 0.06 & 0.02 & 0.01 \\
\hline \multicolumn{2}{|c|}{ Window hole closure with glass $(6 \mathrm{~mm})$} & 120 & & 0.18 & 0.06 & 0.04 & 0.03 & 0.02 & 0.02 \\
\hline
\end{tabular}

a virtual roof with the same superficial area of $G R$ and $M R$, and the theoretically maximum value for the sound absorption coefficient (1.0). The interior covered building's volume is around $38,145 \mathrm{~m}^{3}$ (with $R M C$ retracted $-R M C r$ ) and $19,600 \mathrm{~m}^{3}$ (with $R M C$ extended - RMCe). It should be noted that $R M C$ do not completely cover the ETFE membrane roof solution; the RMC only completely cover the main and lateral naves and partially the transept nave. So, the sound energy may still reach the
ETFE membrane when the $R M C$ is extended. For the numerical simulation of $W R$, it is considered a virtual volume of $38,145 \mathrm{~m}^{3}$, i.e., the same volume of $R M C r$.

According to LeCuyer (2008), in contrast to the acoustic performance in large interior spaces, an ETFE membrane cover provides little, or no sound reduction when faces an external noise, e.g., when a tensile membrane surface is excited by heavy rains, it transmits this impact noise into the interior space. Considering this, an experimental study 
conducted by the British Research Establishment (BRE) confirms the high noise levels caused by the rainfall in several interior spaces covered by membrane roofs. When applied to cover atriums and commercial spaces, this acoustic perception of changing weather is considered a positive attribute. However, in spaces that require quiet internal conditions, this can be a problem. The experimental results obtained by BRE (apud Chiu, Noble, and Valmont 2015) compare the noise levels caused by artificial rainfall on glass, polycarbonate and ETFE membrane (with and without noise suppressors), showing that the impact noise caused by rainfall can be suppressed through the addition of a net, or mesh placed on the outer ETFE membrane surface; it reduces the rainfall impact, creating a thin water layer on the membrane, and it has two effects: it increases the mass of the membrane covering, reducing the sound transmission, and reduces the impact of the raindrop itself, which is dissipated over the open mesh/ membrane.

\section{Results and discussion-comparison of refurbishment proposals}

\subsection{Reverberation Time (RT)}

The Reverberation Time is the time the sound pressure level takes to decay $60 \mathrm{~dB}$, after the sound source stops emitting (Carvalho 2018). According to RRAE (Portuguese Noise Code, Decree-Law 129/2002), the average $R T$ values -in the octave bands centred at the $500 \mathrm{~Hz}, 1000 \mathrm{~Hz}$ and $2000 \mathrm{~Hz}$ frequencies-to be considered for auditoriums with volume (V) above $9000 \mathrm{~m}^{3}$, when normally furnished and without occupation, must satisfy the relation: $R T_{\text {mean }} \leq$ $0.05 \mathrm{~V}^{1 / 3}$; as the Carmo's church/MAC volume range between $19,600 \mathrm{~m}^{3}$ and $38,145 \mathrm{~m}^{3}$-space with roof and ceiling extended and retraced, respectively - the maximum mean legal $R T$ should range between 1.3 and $1.7 \mathrm{~s}$.

The predicted $R T$ values, obtained for all Carmo's church/MAC configurations, for frequency bands between $63 \mathrm{~Hz}$ and $8 \mathrm{k} \mathrm{Hz}$ are presented in Figure 9. In order to compare the nave's space with glass and membrane roof solution with the same volumetric conditions, i.e., both with $R M C e$ and $R M C r$, the predicted $R T$ values were also obtained for these configurations. The predicted $R T$ average value at the middle frequency bands (500 to $1000 \mathrm{~Hz}$ ) range from $1.0 \mathrm{~s}(W R)$ to $4.3 \mathrm{~s}$ (GR without ceiling).

It can be seen in Figure 9 that the volume variation, due to membrane ceiling's extension or retraction, influences the nave's space acoustical performance, either in the $G R$ or $R M C$ roof's option. An example of this effect can be found at Edwin Thomas Hall (Akron, Ohio, U.S. A.) volume's variation design (Carvalho 2018).
However, as the ideal $R T$ values, for spaces where music is important, also depend on the music type, a comparison between the predicted value and ideal $R T$ values for different uses is presented in Table 2 . Therefore, all nave's space configurations are evaluated, with respect to music and speech quality, by comparing the predicted reverberation time with the ideal reverberation time for those volumes and functions. Table 2 shows that the $M R+R M C e$ configuration is suitable for most music types in the $500-1000 \mathrm{~Hz}$ frequency band, except for Popular, Organ and Gregorian chorus. However, it shows that $M R+R M C r$ configuration achieved ideal $R T$ values for these last music types, i.e., this dynamic/changeable volume variation with the retractable membrane ceiling system increases the space use for a wider range of music types. In opposition $W R$ (except for popular music) and $G R$ configurations are not suitable for music performance; only $W R$ configuration is suitable for theatre and cinema performance. Regarding this aspect, as the $M R+R M C e$ predicted $R T$ value is $1.8 \mathrm{~s}$ above the maximum ideal RT value for speech performance, it is expected that with the space's occupation (at maximum capacity) the predicted $R T$ value can be reduced and achieve the ideal.

\subsection{Clarity $\left(C_{80}\right)$-music emission}

Clarity is the ratio, in decibels, between the energy received in the first $80 \mathrm{~ms}$ of the received signal and the energy received later (Carvalho 2018). It is an index that defines the musical notes intelligibility and is related to the balance between perceived clarity and reverberation. This criterion is extremely important to acoustically characterize spaces where musical performances are held, as in the present case study. According to Isbert (1998), Clarity is largely influenced by the shape and materials of the envelope, but not by the space's volume. The source/receiver distance is relevant to calculate this parameter. It should be noted that there is not yet an accurate research that defines the best value that this acoustic parameter should take. However, it is known that each musical style admits variations in this index, through the pertinent musical note's articulation for each style.

The average values of $C_{80}$ calculated for the frequency band $500-1000 \mathrm{~Hz}$ is (Figure 10):

- $2.6 \mathrm{~dB}(\sigma=1.01)$ for $W R$;

- $8.2 \mathrm{~dB}(\sigma=1.33)$ for $G R+R M C r$;

- $6.9(\sigma=1.35)$ for $M R+R M C r$;

- $3.2 \mathrm{~dB}(\sigma=0.74)$ for $M R+R M C e$ 


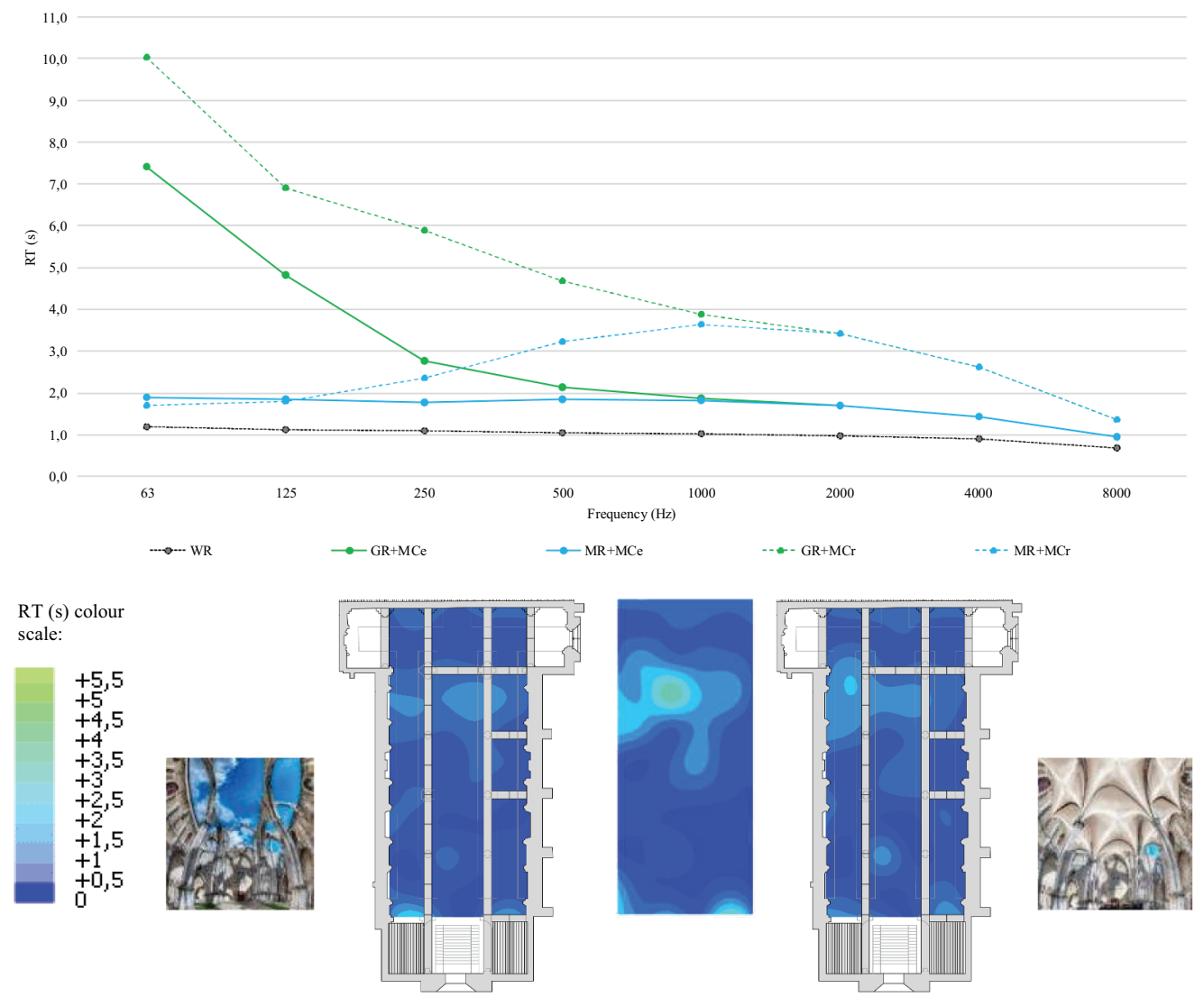

Figure 9. Graphic with reverberation time $(R T)$ for each octave band and distribution maps obtained through numerical simulation by OTL suit-room.

Table 2. Comparison of the ideal $R T$ values (for 500 to $1000 \mathrm{~Hz}$ range), according to the type of use (Carvalho 2018), for each space configuration (values obtained by numerical simulation with OTL suite-room).

\begin{tabular}{|c|c|c|c|c|c|c|c|c|}
\hline \multirow[b]{2}{*}{ Use } & \multirow[b]{2}{*}{ Actual use at naves' space } & \multirow{2}{*}{$\frac{\text { Minimum limit }}{\mathrm{RT}}$} & \multirow[b]{2}{*}{$\begin{array}{l}\text { Ideal } \\
\text { RT }\end{array}$} & \multirow{2}{*}{$\frac{\text { Maximum limit }}{\text { RT }}$} & \multicolumn{4}{|c|}{$\begin{array}{c}\text { Predicted RT (500-1000 Hz) comparison of following } \\
\text { nave's space configurations: }\end{array}$} \\
\hline & & & & & WR & $\begin{array}{l}\mathrm{GR} \\
+\mathrm{RMCr}\end{array}$ & $\begin{array}{l}\mathrm{MR} \\
+\mathrm{RMCr}\end{array}$ & $\begin{array}{l}\text { MR } \\
+\mathrm{RMCe}\end{array}$ \\
\hline & $(\%)$ & (s) & (s) & $(\mathrm{s})$ & $1.0 \mathrm{~s}$ & $4.3 \mathrm{~s}$ & $3.4 \mathrm{~s}$ & $1.8 \mathrm{~s}$ \\
\hline Auditorium (speech) & 12 & 0.6 & $0.7-0.8$ & 0.9 & $x$ & $x$ & $x$ & $x$ \\
\hline Theatre & 12 & 0.6 & $0.7-0.9$ & 1.0 & + & $x$ & $x$ & $x$ \\
\hline Cinema & 8 & 0.7 & $0.8-1.0$ & 1.1 & ++ & $x$ & $x$ & $x$ \\
\hline Music Opera (non-Wagner) & - & 1.2 & $1.3-1.7$ & 1.8 & $x$ & $x$ & $x$ & + \\
\hline (Wagner) & - & 1.7 & $1.8-1.9$ & 2.0 & $x$ & $x$ & $x$ & ++ \\
\hline of chamber & - & 1.3 & $1.4-1.7$ & 1.8 & $x$ & $x$ & $x$ & + \\
\hline Symphony Baroque & - & 1.3 & $1.4-1.6$ & 1.7 & $x$ & $x$ & $x$ & + \\
\hline Classic & - & 1.5 & $1.6-1.8$ & 1.9 & $x$ & $x$ & $x$ & ++ \\
\hline Romantic & 16 & 1.8 & $1.9-2.2$ & 2.3 & $x$ & $x$ & $x$ & + \\
\hline Modern & 32 & 1.4 & $1.4-1.9$ & 2.0 & $x$ & $x$ & $x$ & ++ \\
\hline Popular & 4 & 0.7 & $0.8-1.0$ & 1.1 & ++ & $x$ & $x$ & $x$ \\
\hline Organ & - & 2.4 & $2.5-3.5$ & 3.6 & $x$ & $x$ & + & $x$ \\
\hline Gregorian chorus & 16 & 2.9 & $3.0-4.0$ & 4.1 & $x$ & $x$ & ++ & $x$ \\
\hline
\end{tabular}

++ ideal for this use.

+within the optimum range for this use.

xnot suitable for this use.

The degree of dispersion of the values by frequency range is relatively high (Figure 10). Finally, $C_{80}$ decreases as the source/receiver distance increase.

The Clarity parameter values obtained by the numerical simulations were used to evaluate the MAC nave space's acoustics with respect to music. The evaluation results achieved according to ideal $C_{80}$ values (Carvalho 2018) are shown in Table 3.

Regarding $R T$ and $C_{80}$ parameters (Table 3), it can be concluded that none of the configurations under 


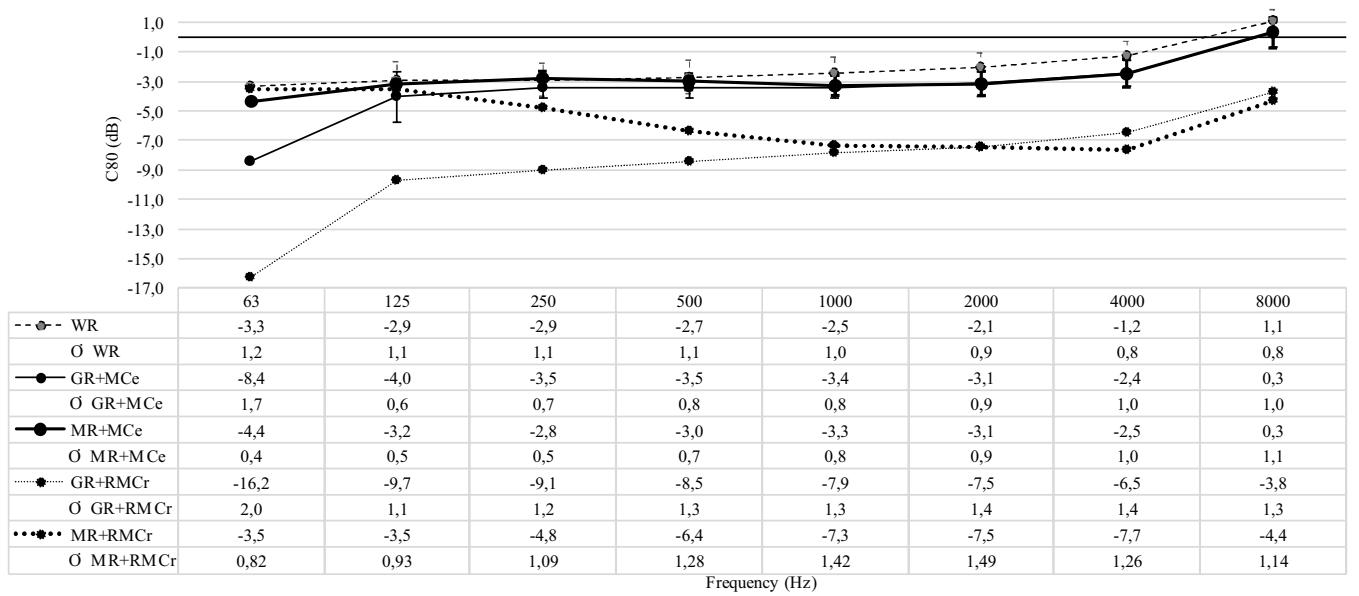

Figure 10. Results of Clarity $\left(C_{80}\right)$ parameter: average for every source/receiver combination and respective standard deviation for each octave band (values obtained by numerical simulations with OTL suite-room).

Table 3. Comparison of the optimum $R T$ and ideal $C_{80}$ values (for 500 to $1000 \mathrm{~Hz}$ range) according to the type of use (Carvalho 2018), for each space configuration (values obtained by numerical simulation, with OTL suite-room).

\begin{tabular}{|c|c|c|c|c|c|c|c|c|c|c|c|c|}
\hline \multirow{2}{*}{\multicolumn{2}{|c|}{ Use }} & \multirow{3}{*}{$\begin{array}{l}\text { Actual use at nave's space } \\
\text { (\%) }\end{array}$} & \multirow{3}{*}{$\begin{array}{l}\text { Optimum } \\
\text { RT } \\
\text { (s) }\end{array}$} & \multirow{3}{*}{$\begin{array}{l}\text { Ideal } \\
C_{80} \\
\text { (dB) }\end{array}$} & \multicolumn{8}{|c|}{$\begin{array}{l}\text { Predicted } R T(500-1 \mathrm{kHz}) \text { and } C_{80}(500-1000 \mathrm{~Hz}) \\
\text { comparison of following nave's space configurations: }\end{array}$} \\
\hline & & & & & \multicolumn{2}{|r|}{ WR } & \multicolumn{2}{|c|}{$\mathrm{GR}+\mathrm{RMCr}$} & \multicolumn{2}{|c|}{$\mathrm{MR}+\mathrm{RMCr}$} & \multicolumn{2}{|c|}{$\mathrm{MR}+\mathrm{RMCe}$} \\
\hline & & & & & $1.0 \mathrm{~s}$ & $-2.6 \mathrm{~dB}$ & $4.3 \mathrm{~s}$ & $-8.2 \mathrm{~dB}$ & $3.4 \mathrm{~s}$ & $-6.9 \mathrm{~dB}$ & $1.8 \mathrm{~s}$ & $-3.2 \mathrm{~dB}$ \\
\hline \multirow{3}{*}{\multicolumn{2}{|c|}{$\begin{array}{l}\text { Auditorium (speech } \\
\text { Theatre } \\
\text { Cinema }\end{array}$}} & 12 & $0.6-0.9$ & 6 & $x$ & $\mathrm{x}$ & $x$ & $x$ & $x$ & $x$ & $x$ & $x$ \\
\hline & & 12 & $0.6-1.0$ & 6 & + & $x$ & $x$ & $x$ & $x$ & $x$ & $x$ & $x$ \\
\hline & & 8 & $0.7-1.1$ & 5 & ++ & $x$ & $x$ & $x$ & $x$ & $x$ & $x$ & $x$ \\
\hline \multirow[t]{10}{*}{ Music } & Opera (non-Wagner) & - & $1.2-1.8$ & 3 till 4 & $x$ & $x$ & $x$ & $x$ & $x$ & $x$ & + & $x$ \\
\hline & (Wagner) & - & $1.7-2.0$ & 1 till 2 & $x$ & $x$ & $x$ & $x$ & $x$ & $x$ & ++ & $x$ \\
\hline & Chamber & - & $1.3-1.8$ & -1 till 1 & $x$ & $x$ & $x$ & $x$ & $x$ & $x$ & + & $x$ \\
\hline & Symphonic Baroque & - & $1.3-1.7$ & 0 till 2 & $x$ & $x$ & $x$ & $x$ & $x$ & $x$ & + & $x$ \\
\hline & Classic & - & $1.5-1.9$ & -1 till 0 & $x$ & $x$ & $x$ & $x$ & $x$ & $x$ & ++ & $x$ \\
\hline & Romantic & 16 & $1.8-2.3$ & -2 till -1 & $x$ & $x$ & $x$ & $x$ & $x$ & $x$ & + & $x$ \\
\hline & Modern & 32 & $1.4-2.0$ & -1 till 0 & $x$ & $x$ & $x$ & $x$ & $x$ & $x$ & ++ & $x$ \\
\hline & Popular & 4 & $0.7-1.1$ & 6 & ++ & $\mathrm{x}$ & $x$ & $x$ & $x$ & $x$ & $x$ & $x$ \\
\hline & Organ & - & $2.4-3.6$ & -2 & $x$ & ++ & $x$ & ++ & + & ++ & $x$ & ++ \\
\hline & Gregorian chorus & 16 & $2.9-4.1$ & -3 till -1 & $x$ & ++ & $x$ & $x$ & ++ & $x$ & $x$ & + \\
\hline
\end{tabular}

++ ideal for this use.

+within the optimum range for this use.

xnot suitable for this use.

analysis present excellent acoustic performance for all uses, particularly when considering $C_{80}$ parameter. Table 3 shows that the predicted $C_{80}$ values for all configurations are not in the range of the ideal $C_{80}$ to the majority of music types (except for Gregorian and organ music). Regarding $R T$ and $C_{80}$ ideal values, $M R+R M C e$ configuration is more acoustical suitable for symphonic and opera music, but, with the $R M C r$ configuration, it provides a suitable setting for organ and choral uses, which are enhanced by a greater reverberance. In comparison, $G R$ configuration only achieves the ideal $C_{80}$ values for organ music and $W R$ for organ and chorus.

Regarding MAC actual main use of nave's space (music events), $M R+R M C e$ configuration is the only one that is suitable for modern symphony music, despite its low $C_{80}$ values. Therefore, in further studies, it is recommended to adopt design measures to improve clarity, as those suggested by Alonso et al. (2014) that consider different types of ephemeral architecture in strategic positions to optimize the acoustic behaviour in a space. According to Alonso et al. (2014), the definition of audience areas, the introduction of stands in the transept elevating the audience sitting further back, and the covering of the cathedral columns closest to these audience areas with velvet draperies constitute positive corrective measures, which allowed the vast space of the transept of the cathedral of Seville to be acoustically adapted for musical performances attended by large audiences.

\subsection{Early decay time (EDT)}

The EDT derives from the reverberation time decay curve and corresponds to six times the time sound takes to decay $10 \mathrm{~dB}$ after the source stops emitting. 
According to Cirillo and Martellotta (2007), in an ideal diffuse space with linear decay, the EDT and $R T$ are the same. However, the first part of the decay is strongly influenced by the initial reflections and, consequently, the $E D T$ is much more sensitive to the relative positions and distance between sources and receivers. When EDT is lower than $R T$, the reverberation sensation is reduced, and, in opposite situation, i.e., when EDT is greater than $R T$, the reverberance sensation increases. These characteristics influence the concept of acoustic environmental quality. The greater presence of reflective surfaces increases the EDT and, consequently, increases the reverberance sensation felt by the listener.

The predicted EDT value for frequency bands between 500 and $1000 \mathrm{~Hz}$ is $2.4 \mathrm{~s}$ (WR), $3.4 \mathrm{~s}(G R), 2.6$ $(M R)$ and $2.1 \mathrm{~s}(M R+R M C e)$. The degree of dispersion of the values, by frequency range (Figure 11), is relatively low for the solutions $W R$ and $M R+R M C e$; there is more variation in the frequency of $63 \mathrm{~Hz}(\sigma=0.2 \mathrm{~s})$ than of $1000 \mathrm{~Hz}(\sigma=0.1 \mathrm{~s})$.
Figure 12 presents a comparative analysis of the $R T$ and $E D T$ results for the frequency bands under study. It shows that $R T$ and $E D T$ predicted values are very close to each other, but $R T$ is always lower than $E D T$, except in the case of $G R$ and $M R$ configurations, where $R T$ is higher than $E D T$; the maximum difference between $E D T$ and $R T$ is $2.0 \mathrm{~s}(W R)$ and $1.2 \mathrm{~s}(M R+R M C e)$ and it occurs at low frequencies $(63 \mathrm{~Hz})$. Among the solutions under analysis, the $M R+R M C e$ solution is the one that presents the closest $E D T$ to the $R T$, i.e., near to the ideal diffuse space.

\subsection{Speech transmission index (STI)}

The STI (Speech Transmission Index) is a measure of speech transmission quality. It is one of the criteria used to characterize word perception. It is a dimensionless parameter that takes values between 0 and 1 ; the closer the value comes to 1 , the better is the intelligibility of the spoken word. Table 4 shows the STI results obtained for each solution in an S01/receiver combination. They are

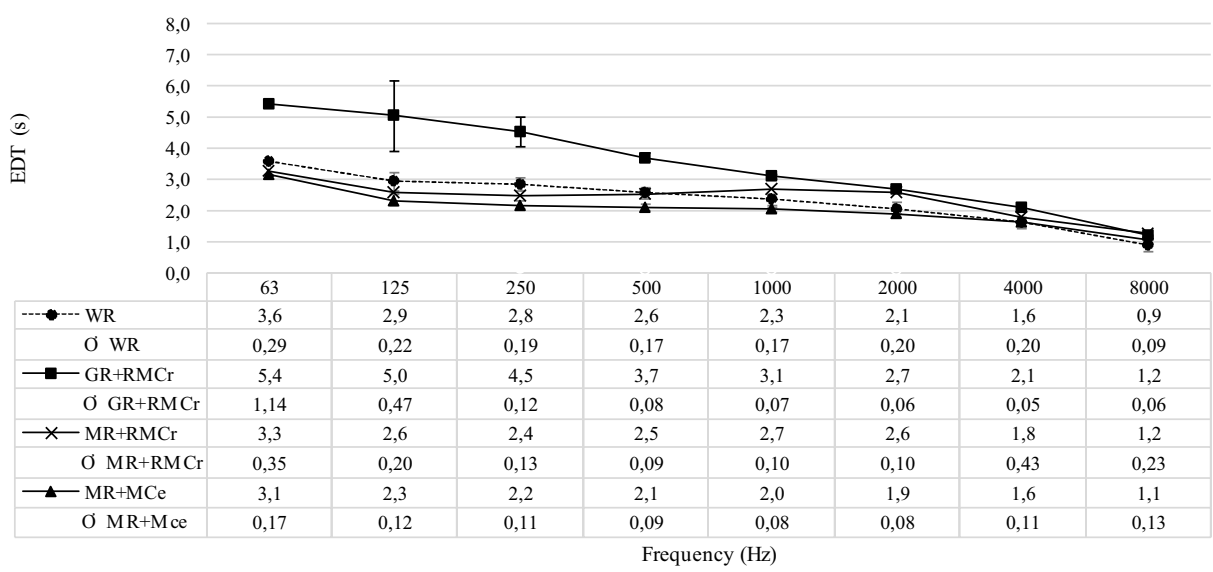

Figure 11. Results for early decay time (EDT) parameter: average for every source/receiver combination and respective standard deviation for each octave band (values obtained by numerical tests with OTL suite-room).

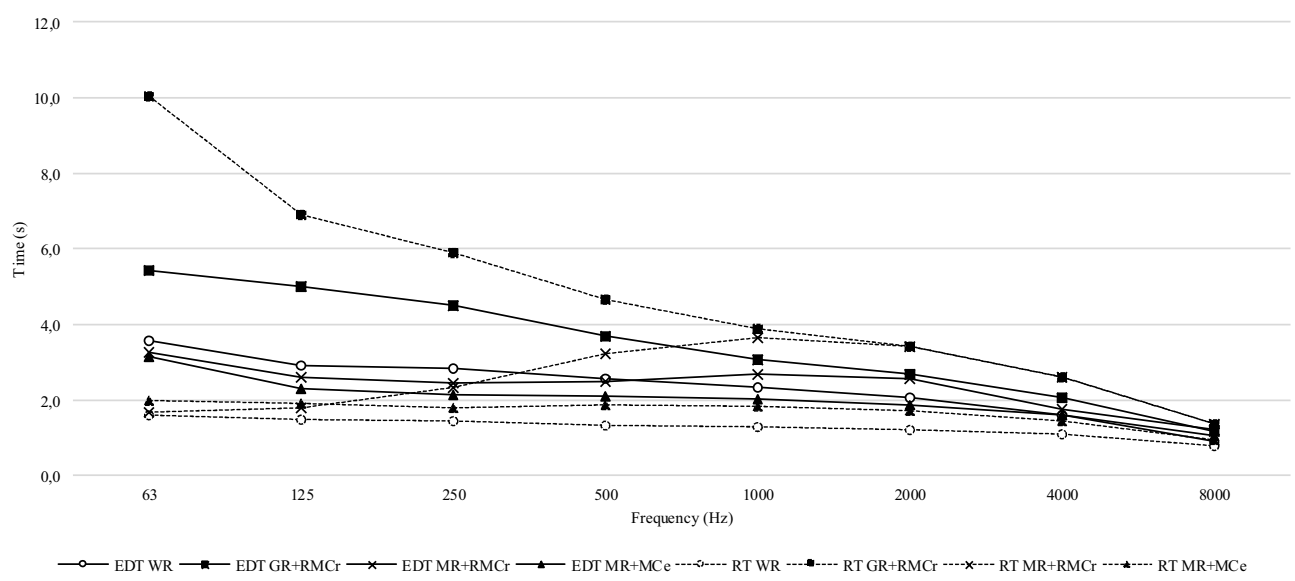

Figure 12. Comparison between predicted reverberation time $(R T)$ and early decay time $(E D T)$ values. 
Table 4. STI for combinations S01/receiver (results obtained by simulation with OTL suite-room).

\begin{tabular}{llllllllllllrr}
\hline & R01 & R02 & R03 & R04 & R05 & R06 & R07 & R08 & R09 & R10 & R11 & R12 & Average \\
\hline W/R & 0.42 & 0.44 & 0.45 & 0.39 & 0.41 & 0.41 & 0.40 & 0.41 & 0.41 & 0.38 & 0.38 & 0.41 & $\mathbf{0 . 4 1}$ \\
GR & 0.26 & 0.27 & 0.24 & 0.26 & 0.24 & 0.25 & 0.24 & 0.24 & 0.23 & 0.23 & 0.24 & 0.24 & $\mathbf{0 . 2 5}$ \\
MR & 0.31 & 0.33 & 0.31 & 0.31 & 0.31 & 0.28 & 0.29 & 0.27 & 0.29 & 0.28 & 0.29 & 0.30 & $\mathbf{0 . 3 0}$ \\
MR+RMCe (extended) & 0.37 & 0.36 & 0.38 & 0.35 & 0.38 & 0.38 & 0.35 & 0.36 & 0.36 & 0.34 & 0,35 & 0,34 & $\mathbf{0 . 3 6}$ \\
\hline
\end{tabular}

Legend: STI/Intelligibility (adapted from Patrício (2010)).

0.00 to 0.29 Null.

0.45 to 0.59 Acceptable.

0.75 to 1.00 Excellent.

0.30 to 0.44 Poor.

0.60 to $0.74 \mathrm{Good}$

scored by a colour scale: the darker the cell is, the better is the result. Except for $G R+R M C r$ configuration, that presents a null score, all solutions are scored as poor (according to the subjective intelligibility scale of the normalized word (Patrício 2010)). The maximum STI mean value $(0.41)$ is attributed to the $W R+R M C r$ configuration, showing that this configuration is slightly more suitable for carrying out activities with word emission than the other ones. These STI results are indicative of poor speech intelligibility. The background noise level used in the modelling was of $75 \mathrm{~dB}$ and it was experimentally obtained in situ.

The high reverberation time values at medium and, especially, high frequencies, prejudice the speech intelligibility of the various space configurations under analysis; as shown in Table 4, the listeners' ability to understand an oral message is poor in all configurations. Therefore, further studies should provide sound absorption at these frequencies, which can be achieved through the design, or presence of more absorbent surfaces, e.g., curtains, carpets or upholstered.

\subsection{Definition $\left(D_{50}\right)$-word emission}

The Definition $\left(D_{50}\right)$ is an acoustic parameter based on the measurement of the reflection energy reaching the receiver in the first $50 \mathrm{~ms}$ after the direct sound arrival, divided by the overall energy received (Patrício 2010), and indicates the speech perception. Normally, these early reflections are considered beneficial because they support the direct sound and contribute to sound audibility, without affecting its quality. It is calculated from the impulse response and it takes values between 0 and 1 ; the closer it is to 1 , the better is the speech definition in a certain environment. The $D_{50}$ mean values calculated for the $500-1000 \mathrm{~Hz}$ frequency band are $0.18(\sigma=0.07)$ for $W R ; 0.04(\sigma=0.02)$ for $G R$; $0.05(\sigma=0.03)$ for $M R$ and $0.17(\sigma=0.05)$ for $M R+R M C e$ (Figure 13). Concluding that $W R$ and $M R+R M C e$ configurations, being $W R$ slightly better, are the closest to the ideal $D_{50}$ value of 1, i.e., for speech use. However, considering only the covered nave's space configurations, $M R$ $+R M C e$ is better than $G R$ and $M R$ configurations.

\section{Conclusions}

The scope of this paper is to evaluate and compare the acoustical behaviour of two functional refurbishment roof/ceiling solutions applied to a heritage building: Carmo's Church/MAC in Lisbon, Portugal, in order to determine the relative acoustic efficiency of architectural membranes (the efficiency of other features will be presented in detail in further research papers). It considers the reintroduction of the roof by using a Membrane $(M R)$ and a Glass $(G R)$ Roof solution and a Retractile Membrane Ceiling $(R M C)$.

The results of this research, summarized in Table 5, indicate that the proposed $M R$ refurbishment solutions would positively influence the acoustic performance of Carmo's church/MAC at the actual state without the roof $(W R)$, being a good acoustic alternative to the GR refurbishment. The predicted values for all acoustic parameters are not within the recommended range for music or speech use, i.e., they do not present an excellent acoustic performance. However, the $M R+R M C$ solution that allows a dynamic ceiling option-retracted (RMCr) or extended (RMCe)-enlarges the range of musical uses for Carmos's church and it would be a better solution to music emission than GR and WR options (Table 5), i.e., replacing both the ceiling and roof would be more favourable than only replacing the roof. Moreover, the present study estimates that the $M R+R M C e$ option would be good for most types of music emission, especially symphonic, which, considering the main target of the Carmo's church ruins/MAC functional refurbishment (music use), makes it the best option. In the perspective of speech use, all refurbishment options present poor behaviour (Table 5 ).

In summary, regarding architectural design and acoustic performance aspects of the best proposed solution ( $M R$ $+R M C e$ ), it is concluded that: (1) the reverberation time values are within the optimal values for symphonic music use; (2) the retractable membrane ceiling would improve the acoustic conditions of the nave's space of the case study -by reducing its volume and improving its sound absorption properties-keeping, at the same time, the architectural language of the original ceiling (ribbed vaults); (3) membrane building technologies are an alternative solution 


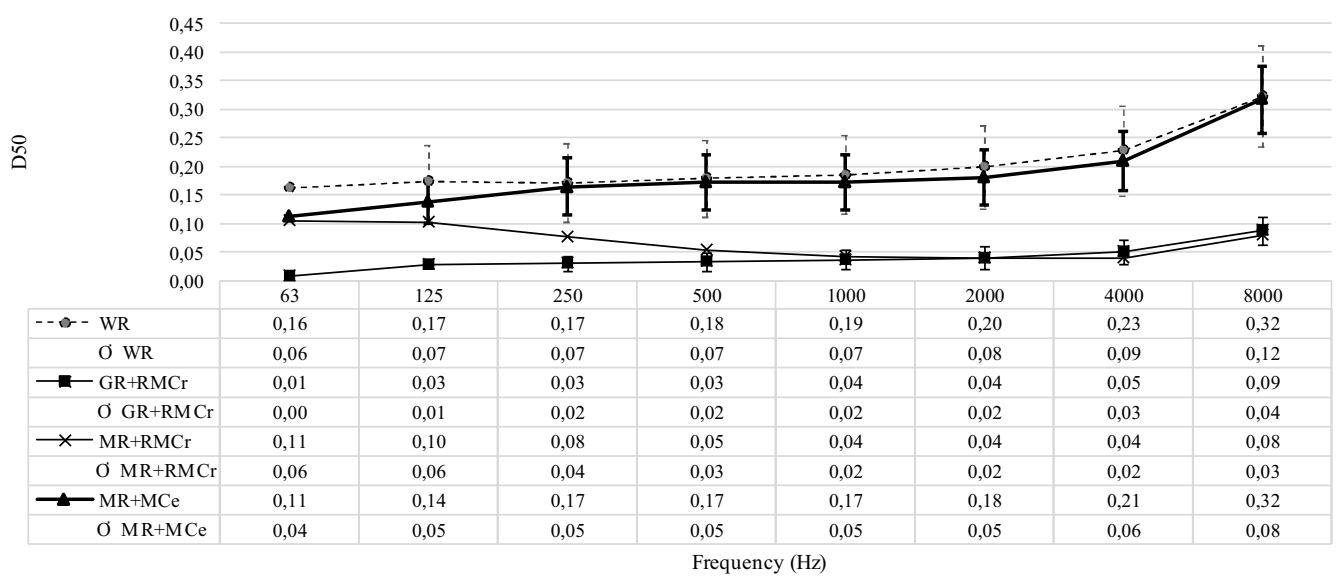

Figure 13. Results of definition $\left(D_{50}\right)$ values: average for every source/receiver combination and respective standard deviation for each octave band (values obtained from numerical simulations with OTL suite-room).

Table 5. Synthesis of optimum values for various acoustic parameters and different uses, mentioned at topic 5 . Summary of the results obtained for the Carmo's church/MAC nave's space-with and without refurbishment solutions.

\begin{tabular}{|c|c|c|c|c|c|c|}
\hline Acoustic parameter & $\begin{array}{c}\text { Speech } \\
\text { optimum range }\end{array}$ & $\begin{array}{l}\text { Music } \\
\text { optimum range }\end{array}$ & WR & GR & MR & $\mathrm{MR}+\mathrm{RMCe}$ \\
\hline RT (s) $(500-1 \mathrm{k} \mathrm{Hz})$ & $0.6<\mathrm{RT}<1.3$ & $1.3<\mathrm{RT}<2.3$ & 1.0 & 4.3 & 3.4 & 1.8 \\
\hline EDT (s) (500-1 k Hz) & $0.6<$ EDT $\leq 1.3$ & $1.3<\mathrm{EDT} \leq 2.3$ & 2.5 & 3.4 & 2.6 & 2.2 \\
\hline $\mathrm{C}_{80}(\mathrm{~dB})(500-1 \mathrm{k} \mathrm{Hz})$ & $C_{80 m} \quad 4.0$ & $-4.0 \leq C_{80} \leq 4.0$ & -2.6 & -8.2 & -6.9 & -3.2 \\
\hline$D_{50}(500-1 \mathrm{k} \mathrm{Hz})$ & $D_{50} \quad 0.50$ & $D_{50} \leq 0.50$ & 0.18 & 0.04 & 0.05 & 0.17 \\
\hline $\begin{array}{l}\text { STI } \\
\text { (intelligibility's scale) }\end{array}$ & \multicolumn{2}{|c|}{$\begin{array}{l}0.00-0.29 \text { (null); } 0.30-0.44 \text { (poor); } \\
0.45-0.59 \text { (acceptable); } \\
0.60-0.74 \text { (good); } 0.75-1.00 \text { (excellent) }\end{array}$} & 0.41 & 0.25 & 0.30 & 0.36 \\
\hline \multirow[t]{5}{*}{ Speech use } & RT & & + & $x$ & $x$ & $x$ \\
\hline & EDT & & $x$ & $x$ & $x$ & $x$ \\
\hline & $\mathrm{C}_{80}$ & & $x$ & $x$ & $x$ & $x$ \\
\hline & $D_{50}$ & & $x$ & $x$ & $x$ & $x$ \\
\hline & STI & & poor & null & poor & poor \\
\hline \multirow[t]{5}{*}{ Music use } & RT & & $x$ & $x$ & $x$ & + \\
\hline & EDT & & $x$ & $x$ & $x$ & + \\
\hline & $\mathrm{C}_{80}$ & & $x$ & $x$ & $x$ & + \\
\hline & $D_{50}$ & & + & + & + & + \\
\hline & STI & & poor & null & poor & poor \\
\hline
\end{tabular}

Legend:

+ Within the optimum range for this use.

xNot suitable for this use.

suitable for acoustic refurbishment interventions, especially in the cases where old/historic walls/surfaces are very reflective and cannot be changed for heritage protection.

The analysis of the predicted acoustic comfort parameters inside the MAC with $M R+R M C e$ option suggests the following considerations: (1) $R T$ predicted values estimate the room is very reverberant for speech use (with values near twice as high as the optimal), but are within the range for the majority of music types; (2) EDT predicted values are close to the predicted $R T$ values, i.e., near the ideal diffuse space; (3) $C_{80}$ values are not within the ideal range of values to the majority of music uses, except for Gregorian chorus and organ music; (4) $D_{50}$ values are not acceptable with respect to speech; (5) STI values allow classify the hall as poor.
The reverberation time in the case study's space is significantly influenced by the material used in the roof and ceiling. With the alternative membrane solution $M R+R M C r$ or $M R+R M C e-$ a significant reduction in the reverberation time values is achieved, even compared to the conventional glass solution in the same condition - GR+RMCr or GR+RMCe - for medium and low-frequency bands, respectively.

Note that the available information on the acoustic properties of architectural membranes is scarce and not detailed by the producers and suppliers of these materials. To gain more confidence in these results, it would be advisable to perform experimental tests with multilayer membrane solutions. In addition, more analysis and modelling for each evaluated parameter and configurations should be done: (1) to completely explore the topics raised 
in this paper; (2) to improve membrane's proposal, ideally with dynamic remedial solutions, such as those referred at literature review, in order to achieve an optimum acoustic comfort, for both speech and music uses.

\section{Acknowledgment}

Authors also thanks to: PEMARD (Mediterranean Acoustics Research \& Development) for the permission to use the Olive Tree Lab Suite (OTL) software; Archaeologists José Morais Arnaud and Célia Pereira, for the collaboration and information provided about the Carmo's Archaeological Museum.

\section{Acronyms list}

ETFE

Ethylene Tetrafluoroethylene

HC

Historical Construction

$M A W$

Membranes with Additional Weights

$M A C$

Museum of Archaeology of Carmo MAC

GR

Glass Roof

$M R+R M C$

Membrane Roof with a Retractile Membrane Ceiling

WR

Without Roof

RMCr

Retractile membrane ceiling retracted

RMCe

Retractile membrane ceiling extended

$R T$

Reverberation Time

$\mathrm{C}_{80}$

Clarity

EDT

Early Decay Time

STI

Speech Transmission Index

$D_{50}$

Definition

\section{Disclosure statement}

No potential conflict of interest was reported by the authors.

\section{Funding}

Portuguese Foundation for Science and Technology (FCT Fundação para a Ciência e Tecnologia), Portuguese Ministry of Education and Science (MEC - Ministério da Educação e Ciência) and European Social Fund (ESF) with the reference grant SFRH/BD/104891/2014.roject UID/AUR/04509/2013 funded by FCT and MEC by national funding and FEDER (Fundo Europeu de Desenvolvimento Regional) co-financing under the new PT2020 (Portugal 2020) in a partnership agreement with Lab2PT, School of Architecture/University of Minho, Portugal.Project POCI/01/0145/FEDER/007457 funded by FEDER funds through COMPETE2020 (Programa Operacional Competitividade e Internacionalização) in a partnership agreement with CONSTRUCT Institute of R\&D in Structures and Construction of Faculty of Engineering/ University of Porto, Portugal.

\section{ORCID}

Macieira Mónica (D) http://orcid.org/0000-0001-7591-5406

Paulo Mendonça (D) http://orcid.org/0000-0003-2932-321X João Miranda Guedes (D) http://orcid.org/0000-0002-58036036

António P. O. Carvalho (D) http://orcid.org/0000-0002-68843894

\section{References}

Alonso, A., J. Sendra, R. Suárez, and T. Zamarreño. 2014. Acoustic evaluation of the cathedral of Seville as a concert hall and proposals for improving the acoustic quality perceived by listeners. Journal of Building Performance Simulation 7 (5):360-78. doi:10.1080/ 19401493.2013.848937.

Álvarez-Morales, L., T. Zamarreño, S. Girón, and M. Galindo. 2014. A methodology for the study of the acoustic environment of Catholic cathedrals: Application to the Cathedral of Malaga. Building and Environment 72:102-15. doi:10.1016/ j.buildenv.2013.10.015.

Arnault, J., and C. Fernandes. 2005. Building the memory: The collections of the Carmo's Archaeological Museum (in Portuguese). Lisbon: Association of Portuguese Archaeologists (in Portuguese).

Berger, H. 1996. Light structures, structures of light: Form and function of tensile architecture. Basel: Birkhäuser.

Carvalho, A. 1994. Influence of architectural features and styles on various acoustical measures in churches. Ph.D. thesis, U. of Florida, U.S.A.

Carvalho, A. 2018. Environmental and building acoustic (in Portuguese) 8.14 edition. Departamento de Engenharia Civil, mestrado integrado em engenharia civil, Setembro. Porto, Portugal: Faculdade de Engenharia da U. do Porto. 
Charalampous, P., and P. Economou. 2016. An improved user-independent algorithm for room acoustic parameters calculations. 23rd International Congress on Sound \& Vibration, Athens, Greece, July 10-14.

Chemlik, V., D. Urbán, M. Rychtáriková, and C. Glorieux. 2015. The use of textile membranes in architectural acoustics. An overview. Euro Noise 2015, 31 May 3 June. Maastricht: EAA-NAG-ABAV.

Chiu, S., D. Noble, and E. Valmont. 2015. Acoustic in architectural fabric structures: The case of ETFE pillows. In Fabric structures in architecture, ed. J. LLorens. United Kingdom: Woodhead Publishing Series in Textiles 2015, pp. 241-256.

Cirillo, E., \& Martellotta, F. 2007. Worship, Acoustics and Architecture. Building Acoustics, 14(3),241-241. doi: doi.10.1260/135101007781998938

Dlhy, D., and K. Minarovicova. 2014. Acoustic quality of interior space - Options for its improvement. Akustika 3: s.217-30.

Iannace, G. 2016. Acoustic correction of monumental churches with ceramic material: The case of the Cathedral of Benevento (Italy). Journal of Low Frequency Noise, Vibration and Active Control 35:230-39. doi:10.1177/ 0263092316661028.

IEC 60268-16. 2011. Sound system equipment - Part 16: Objective rating of speech intelligibility by speech transmission index.

Isbert, A. 1998. Acoustic design of architectural spaces (in Spanish). Barcelona: Edicions UPC.

ISO 3382-1. 2009. Acoustics - Measurement of room acoustic parameters. Part 1: Performance spaces.

ISO 3382-2. 2008. Acoustics - Measurement of room acoustic parameters. Part 2: Reverberation time in ordinary rooms.

ISO 3382-3. 2012. Acoustics - Measurements of room acoustic parameters. Part 3: Open Plan Offices.

Joyce, W. B. 1974. Sabine's formula. The Journal of the Acoustical Society of America 55 (S1):S12-S12. doi:10.1121/1.1919556.

Karabiber, Z., and Ö. Denli. 1997. Architectural acoustics and old buildings, proceedings of. International congress on studies in ancient structures, 157-66. YTU Faculty of architecture, Istanbul, Turkey.

Lam, Y. 2005. Issues for computer modelling of room acoustics in non-concert hall settings. Acoustical Science and Technology 26:145-55. doi:10.1250/ast.26.145.

LeCuyer, A. 2008. ETFE technology and design. Berlin: Brikhauser.

Llorens, D., and B. A. Soldevila. 1991. Caracteristicas arquitetónicas de las construcciones textiles. Informes de la construcción 43 (413):23-29. doi:10.3989/ic.1991.v43. i413.1375.

Lombardi, I., and A. Trematerra. 2018. The acoustic correction of monumental churches: The case of the "Duomo of Ravello" (Italy). Euronoise 2018 - Conference Proceedings, Crete, Greece.

Lombardi, I., S. Cicala, G. Iannace, and A. Trematerra. 2017. The acoustic characteristics of the "dives in misericordia" church. Proc. Internoise 2017, Hong Kong, China.

Maa, D.-Y. 1975. Theory and design of microperforated panel sound-absorbing constructions. Scientia Sinica 18 (1):55-71.

Macieira, M., P. Mendonça, and J. Guedes. 2017. Architectural membranes on building's functional refurbishment. ICBMM
2017; IOP Publishing. IOP Conference Series: Materials Science and Engineering 264:012005. doi:10.1088/1757-899X/264/1/ 012005.

Monjo Carrió, J. 1985. La arquitectura têxtil. Informes de la Construcción 36:367. Madrid. doi:10.3989/ic.1985.v36. i367.1838.

Monumentos. 2017. Carmo Convent's Church/Carmo's Archaeological Museum (in Portuguese). Accessed April 2, 2017. http://www.monumentos.gov.pt/site/APP PagesUser/SIPA.aspx?id=6521.

Navarro, J., J. Sendra, and S. Muñoz. 2009. The Western Latin church as a place for music and preaching: An acoustic assessment. Applied Acoustics 70:781-89. doi:10.1016/j. apacoust.2008.09.014.

Nocera, F., A. Gagliano, G. Evola, and M. Gioia. 2014. Acoustic quality of a tensile membrane structure used as a lecture hall, and proposals for its improvement. Building Acoustics 21 (4):287-304. doi:10.1260/1351010X.21.4.287.

Nocke, C., C. Hilge, and J. Scherrer. 2011. Micro-perforated sound absorbers in stretched materials. Proceedings of ACOUSTICS 2011, Gold Coast, Australia, November 2-4.

Nocke, C., C. Hilge, and J. Scherrer. 2016. Transparent micro-perforated sound absorbers revisited. Proceedings of the 22nd International Congress on Acoustics, Buenos Aires, Argentina, September 5-9.

Novak, J. 2004. Bending-wave energy propagation in inhomogeneous thin plates and membranes. Inter-noise 2004, Prague, Czech Republic.

Patrício, J. 2010. Acoustics in buildings (in Portuguese). 6th ed. Portugal: Verlag Dashöfer.

PEMARD. 2018. Olive tree lab suite (Version 4.3) [computer software]. Cyprus: P. E. Mediterranean Acoustics Research \& Development Ltd. Accessed March 21, 2018. https:// www.mediterraneanacoustics.com/help-files.html.

Pereira, C. 2017. The church and the convent of Santa Maria do Carmo in Lisbon (1389-1755) (in Portuguese). Lisbon: Association of Portuguese Archaeologists and Carmo's Archaeology Museum (in Portuguese).

RRAE - Decreto-Lei n.129/2002, 11 May, Decree-Law n. 96/ 2008, 9 June. Portuguese Legislation for Buildings Acoustic Requirements (in Portuguese), Chapter 2, Article 10 -A1 a).

Simões, F. 2000. Comportamiento acústico de espácios cubiertos com estructuras textiles. PhD thesis, Escuela Técnica Superior de Arquitectura. U. de Sevilha.

Toyoda, M., and D. Takahashi. 2013. Reduction of rain noise from Ethylene/TetraFluoroEthylene membrane structures. Applied Acoustics 74:1309-14. doi:10.1016/j. apacoust.2013.05.013.

Tronchim, L., and M. Coralli. 2010. The acoustic design proposed for a church's transformation into auditoria. Proceedings of the International Symposium on Room Acoustics, ISRA 2010, Melbourne, Australia, August 29-31.

Yatzer. 2016. Gymnasium transformed into concert hall. Accessed January 11. https://www.yatzer.com/gymtransformed-concert-hall-pannonhalma-archabbeyhungary.

Zanelli, A. 2015. Architectural fabric structures in the refurbishment of archaeological and cultural heritage areas. In Fabric structures in architecture, ed. J. LLorens, 481-527. Woodhead Publishing Series in Textiles 2015, United Kingdom. 